\title{
INCLUSÃO SOCIAL NO CONTEXTO DO PROUNI E SUAS CONTRADIÇÕES
}

\author{
Maria das Graças Martins da Silva \\ Universidade Federal de Mato Grosso \\ Manira Perfeito Ramos da Silva \\ Universidade de Cuiabá
}

\section{Resumo:}

O texto debate a inclusão social e suas contradições no âmbito do PROUNI. Para tanto, identifica-se como se expressa a inclusão social em documentos, discursos oficiais e depoimentos de bolsistas vinculados ao Programa em uma universidade privada. As evidências são de que os processos de inclusão são convenientes ao sistema social e que há uma antinomia entre essa categoria e a de igualdade. Os depoimentos revelam mudanças na vida material dos estudantes, no seu modo de ver o mundo e em sua existência. Conclui-se que incluir prendese às limitações da ordem social estabelecida, podendo, contraditoriamente, suscitar elementos que a desafiam.

Palavras-chave: Política educacional; PROUNI; inclusão social. 


\title{
SOCIAL INCLUSION IN THE CONTEXT OF PROUNI AND CONTRADICTIONS
}

\begin{abstract}
:
The text discusses the social inclusion and its contradictions within the PROUNI. For this, identifies as expressed social inclusion in official documents, speeches and statements of scholars linked to the Program at a private university. The evidence is that the processes of inclusion are convenient to the social system and that there is a contradiction between this category and the equality. Reports reveal changes in the material life of the students, their way of seeing the world and in their lives. There are limitations to include in the established social order, may, paradoxically, forge elements that challenge.
\end{abstract}

Key words: Educational Policy; PROUNI; social inclusion. 


\section{Introdução}

O texto tem por objetivo debater a ideia de inclusão social no âmbito do Programa Universidade para Todos (PROUNI), evidenciando contradições que se apresentam. Não obstante os limites que ao texto se impõem, aspectos abordados podem contribuir para um balanço da realidade em tela, decorrido dez anos da criação do referido Programa.

Para alcançar o objetivo, identifica-se como se expressa a inclusão social em documentos, discursos oficiais e depoimentos de bolsistas vinculados ao PROUNI em uma universidade privada, mediando os dados com análises que tratam do tema.

Como amplamente divulgado, o PROUNI foi instituído pela Lei nº11.096, de 13 de janeiro de $2005^{1}$, propondo-se a conceder bolsas parciais e integrais em instituições privadas de ensino superior com fim ou sem fim lucrativo, para alunos provenientes do ensino público ou do ensino privado na condição de bolsista integral. Em contrapartida, as Instituições de Ensino Superior(IES)recebem isenção fiscal de tributos federais, no período de vigência da adesão. Segundo o critério socioeconômico, podem candidatarse às bolsas integrais estudantes com renda familiar, por pessoa, de até um salário mínimo e meio e às bolsas parciais os candidatos com renda familiar de até três salários mínimos, por pessoa. Há no Programa uma preocupação em formar professores da rede pública de ensino básico; por isso, esses profissionais que concorrem a bolsas em cursos de licenciatura, curso normal superior ou de pedagogia não precisam cumprir o critério de renda, desde que em efetivo exercício e do quadro permanente da escola. Considera-se, ainda, cota racial na ocupação de bolsas, segundo a proporcionalidade de cor divulgada no último censo demográfico (Lei n. ${ }^{\circ}$ 11.096, de 2005).

\footnotetext{
${ }^{1}$ Segundo dados do Censo Demográfico e Contagem da População de 2010 do IBGE, as menores faixas de renda registravam percentual maior entre pretos e pardos, enquanto as maiores faixas de renda possuíam um percentual maior entre brancos. Não obstante, houve um crescimento da renda de negros e pardos no período de 2001 a 2011, apontado pelo IPEA (2012), visto que a renda dos pretos e pardos subiu 66,3\% e 85,5\%, respectivamente, contra $47,6 \%$ dos brancos.
}

Olh@res, Guarulhos, v. 3, n. 1, p. 76-103. Maio, 2015. 
Presente em todos os estados da federação, o PROUNI abre possibilidade de ingresso na educação superior a quem se vê afetado por essa questão, o que pode explicar a sua aceitação, a julgar pelo salto quantitativo nas inscrições aos processos seletivos. A título de exemplo: em 2005 foram 422.521 inscrições, ao passo que no primeiro processo seletivo de 2012 foram 1.098 .856 .

Os números são expressivos, sugerindo uma política pública que se afirmou. Constata-se que em 2013 somavam 1.217.179 bolsistas, distribuídos em ensino presencial e a distância, em Faculdades, Centros Universitários e Universidades, em instituições privadas com e sem fins lucrativos, em cursos tecnológicos, de licenciatura e bacharelado. O quadro, portanto, com diversificados formatos e contextos de realização da formação do estudante, sinaliza distintos níveis de qualidade de ensino. ${ }^{2}$

O termo inclusão é associado com recorrência ao PROUNI, sob um discurso ufanista e que aponta para a possibilidade de escalada social. Isso é ilustrado na comemoração alusiva aos dez anos do Programa, na Comissão de Educação da Câmara dos Deputados, que protagonizou em 20 de maio de 2014 o seminário "Dez anos do PROUNI - Balanço e Perspectivas". Ali, o deputado que promoveu o evento manifestou: "O PROUNI se revela num grande sucesso educacional, que ampliou largamente o acesso dos jovens de baixa renda ao ensino superior no Brasil" (JORNAL DA CIÊNCIA, veiculado em 20 de maio de 2014).

Cabe ressaltar a emblemática chamada de uma matéria publicada sobre o evento: "Em dez anos, ProUni já formou 400 mil profissionais. Metade é negra. Neste período, 1.923 médicos bolsistas foram formados". No complemento ao título, foi citada a fala da então presidenta da UNE: "Eles acessam um mundo que até então foi negado às periferias do nosso país".

${ }^{2} \mathrm{O}$ IGC (Índice Geral de Cursos) refere-se a um indicador que leva em conta o desempenho dos estudantes no ENADE (Exame Nacional de Desempenho dos Estudantes), a avaliação da infraestrutura das instituições de ensino superior e a formação do corpo docente. Na avaliação de 2011, entre 2.136 universidades e faculdades avaliadas, apenas 27 atingiram o conceito máximo de qualidade atribuído pelo MEC. Chama atenção que $27 \%$ das faculdades não alcançaram a nota mínima estipulada pelo MEC. (Disponível em: educacao.uol.com.br/ranking-de-cursos/. Acesso em: 25 de maio de 2014).

Olh@res, Guarulhos, v. 3, n. 1, p. 76-103. Maio, 2015. 
A notícia expõe, ainda, a frase do secretário de Educação Superior do Ministério da Educação, Paulo Speller: "É um programa efetivamente de inclusão social." (REDE BRASIL ATUAL, veiculado em de 20 de maio de 2014).

Contudo, avaliações críticas sustentam que o Programa contribui para aprofundar o quadro de privatização da educação superior e para a disseminação de um ensino precarizado (MANCEBO, 2004; LEHER, 2004; SGUISSARDI, 2006; CUNHA, 2007; GOERGEN, 2010; CHAVES, 2010). De fato, os números referentes à cobertura do PROUNI demonstram que se trata de uma política priorizada pelo poder público; entretanto, tal magnitude pode camuflar aspectos essenciais, como o nível do ensino realizado, a natureza do espaço público e o uso do recurso público.

Frente ao debate polêmico, é importante ter como referência que a certificação no nível superior dos segmentos carentes represente, efetivamente, uma promoção humana ${ }^{3}, o$ que contribui para examinar criticamente o PROUNI como uma política educacional.

A categoria contradição, na perspectiva do método dialético, mostra-se válida para abordar o desenvolvimento do fenômeno estudado. Contradição representa as forças que são próprias ao fenômeno em si, bem como as que lhe são externas, envolvendo movimentos, mediações e relações. Significa que os polos contrários coexistem, afetam-se, condicionam-se mutuamente e tendem, em condições determinadas, a se converterem no seu oposto, possibilitando explicar mudanças e transformações das coisas (MAO, 2009). Por essa base, se põe a questão chave: o que significa o PROUNI, como um programa dito de inclusão?

\footnotetext{
${ }^{3}$ Por inspiração em Saviani (2000, p. 38), educação refere-se a um processo de comunicação entre pessoas livres em graus diferentes de maturação humana, que visa a promoção humana, o que quer dizer tornar as pessoas "cada vez mais capazes de conhecer os elementos de sua situação para intervir nela transformando-a no sentido de uma ampliação da liberdade, da comunicação e colaboração" entre todos.

Olh@res, Guarulhos, v. 3, n. 1, p. 76-103. Maio, 2015.
} 


\section{Decifrando a ideia de inclusão}

O debate da inclusão vincula-se ao da igualdade e traduz projeto(s) de sociedade. No que segue, essa densa questão é tratada tangencialmente pela necessidade de concisão do texto.

Encontra-se em Giddens (2001) a ideia de nivelamento entre inclusão e igualdade. O idealizador da terceira via, projeto social ou modelo programático tendo em vista "se ajustar as novas circunstâncias da era global” (p. 82), assim expressa: "A nova política define igualdade como inclusão e a desigualdade como exclusão [...]" (p. 112).Tal projeto social, em síntese, com as nivelações que apresenta, tem por base uma sociedade determinada pelo modo de produção capitalista, portanto, sustentada no valor da mercadoria, embora professe a necessidade de atenuar os seus efeitos catastróficos e se anuncie em condições de oferecer "igualdade de oportunidades" e justiça social.

Em oposição a essa vertente, pondera-se que a existência social pautada nas relações sociais capitalistas tem como fundamento a desigualdade. Nesse sentido, tendo em vista a lógica inerente ao modelo de sociedade, há incoerência no fato de uma política pública se apresentar como combatente da desigualdade, já que essa compõe, em essência, o sistema social que vige. Assim sendo, em virtude da materialidade social e seus condicionamentos ${ }^{4}$ entende-se que o discurso da inclusão reveste-se de aparências.

A propósito, cabe o exame de Mészáros (2002) acerca de que o aspecto mais problemático do sistema social sob a égide do capital é a sua incapacidade de tratar as causas como causas, optando por administrá-las por meio de ajustes nos efeitos que promove. As contradições são, por isso, justificadas, idealizadas, na perspectiva da reprodução das relações sociais.

\footnotetext{
${ }^{4}$ Dado os limites do texto, indica-se Mészáros (2002) para aprofundamento da questão. Segundo o autor, o conceito de mediações de segunda ordem representa as hierarquias estruturais de dominação e subordinação que configuram o sistema de metabolismo social do capital, decorrentes da propriedade privada e da divisão alienada do trabalho.
} 
Nessa linha, a rigor, os conceitos de inclusão e de igualdade se antagonizam, considerando que as políticas de inclusão não se propõem a efetivar a igualdade e, sim, amenizar as desigualdades, permitindo aos desiguais (se incluídos) o acesso a certos bens, e em certa medida. Sobre isso, Almeida (2009) explica:

\begin{abstract}
A compreensão de que a política social, em especial a denominada de inclusiva, preconiza o acesso aos direitos e utiliza-se de programas para efetivar ações que minimizem as desigualdades sociais, demonstra que o Estado vem seguindo uma lógica específica: a de que essas justificativas (sob o rótulo do discurso de inclusão) são efetivadas em um sistema em que o capital é o ator principal e que nenhuma política desenvolvida sob essa orientação é desvinculada dessa lógica. (ALMEIDA, 2009, p. 43).
\end{abstract}

Tais considerações permitem avaliar a inclusão não articulada à igualdade, mas, sim, à condição de exclusão, visto que, como as políticas de inclusão não enfrentam a causa da desigualdade (por ser intrínseca ao funcionamento do sistema social), sempre haverá excluídos do acesso aos bens sociais fundamentais, justificando, assim, a implantação de medidas inclusivas. A partir disso, conclui-se que o modo de produção pressupõe ou faz conviver inclusão com exclusão, o que, do ponto de vista da ordem estabelecida, precisa ser periodicamente ajustado, tratado, enfatizado.

Segundo Oliveira (1997), a exclusão é atribuída ou aparece socialmente ligada à falta de habilidades dos indivíduos para que sejam absorvidos pelos novos processos produtivos. Argumenta, ainda, que esse grupo se torna economicamente "desnecessário" ao sistema produtivo, embora útil como regulador do uso ou do valor da força de trabalho. Os ciclos articulados do incluir/excluir, portanto, expressam uma função econômica, embora não menos importante seja a ideológica, que, pelo acolhimento de segmentos excluídos, controla ou ameniza tensões sociais próprias da sociedade desigual.

Ao considerar o aspecto ideológico, em relação à pesquisa em foco, nota-se que os termos educação inclusiva, inclusão social, democratização, Olh@res, Guarulhos, v. 3, n. 1, p. 76-103. Maio, 2015. 
igualdade, acesso inclusivo, entre outros, são explorados e se apresentam com uma aparência de superação do sistema de exclusão.

Nesse sentido, Boneti (2005) acredita que a noção de cidadania conserva uma proximidade com o discurso de estar incluído.

[...] a pessoa "incluída" seria a pessoa juridicamente cidadã, isto é, com direitos e deveres frente ao contrato social, com direitos e deveres de votar e ser votado e usufruir dos direitos sociais básicos. Pode-se dizer que esta concepção de cidadania restringe o indivíduo a uma posição passiva na sociedade, isto porque garante-se a participação do indivíduo por vias formais, na medida em que este indivíduo é "incluído" formalmente, juridicamente, como cidadão que vota, que tem opinião, que produz. (BONETI, 2005, p. 4).

Peixoto (2010, p. 226), por sua vez, acrescenta que o termo exclusão relaciona-se às configurações que tornaram a sociedade mais heterogênea "com novas demandas, novos sujeitos coletivos e eixos de desigualdade, que rompem com a sociedade estabilizada em divisões de classe e polarizada de modo mais unidimensional e linear". O exame indica que a inclusão nas políticas sociais se estende a outros eixos de desigualdades, como os étnico-raciais, de gênero, religiosos, de condições físicas e de opção sexual.

Ainda segundo Peixoto (2010, p. 238), os termos inclusão e exclusão “[...] aludem, portanto, a uma relação espacial, em que os verbos se complementam e se opõem e trazem, implícita, a compreensão de uma relação centro-periferia." A autora entende que o conceito de inclusão embute uma carga valorativa positiva (noção de direitos humanos, proteção) e, na exclusão, essa carga se mostra negativa. Sob essa interpretação, o Estado, ao divulgar uma ação como inclusiva, usaria a carga valorativa positiva em seu discurso, obscurecendo as formas "às vezes indignas de inclusão" (p. 241).

Uma breve tomada sobre documentos que expressam políticas públicas, a luz do enfoque tratado, tem como marco a Lei de Diretrizes e Bases- LDB (Lei n. $\left.{ }^{9} 9.394 / 1996\right)$, ainda que ali não figure a palavra inclusão. A Lei 
estabelece como um dos princípios e fins da Educação Nacional, no art. $3^{\circ}$ item I, a igualdade de condições para o acesso e permanência na escola, argumento explorado nas políticas públicas que se anunciam como inclusivas.

Para Souza e Bonilla (2009), o termo inclusão digital, a partir do ano 2000, se destacou com a implementação do Programa Sociedade da Informação. Os autores alertam que nesse período eram pensadas ações para inclusão digital sem uma relação com as problemáticas sociais, ou seja, os "excluídos" eram incluídos enquanto consumidores.

A expressão inclusão social ganha dimensão, sobretudo, no âmbito das ações afirmativas, como se observa na Portaria n. ${ }^{\circ} 1.156$ do Ministério da Justiça, de 20 de dezembro de 2001, que institui o Programa de Ações Afirmativas no Ministério da Justiça.

Há de se destacar que, em maio de 2012, foi julgada no Supremo Tribunal Federal a legalidade das cotas nas instituições federais de ensino superior. Ao ser tratada pelo Judiciário, a referida questão traduz um momento de luta do movimento organizado por uma sociedade com menor grau de desigualdade social.

Ressalta-se a Lei n. ${ }^{\circ} 12.711$, em vigor em 12 de agosto de 2012, dispondo sobre cotas no ingresso nas instituições federais de ensino superior, de modo a que reservem, em cada concurso seletivo para ingresso nos cursos de graduação, por curso e turno, no mínimo $50 \%$ de suas vagas para estudantes que tenham cursado integralmente o ensino médio em escolas públicas. A Lei complementa que no preenchimento das vagas 50\% deverão ser reservados aos estudantes oriundos de famílias com renda igual ou inferior a 1,5 salários-mínimos per capita.

Na visão de Vieira (2007 apud ALMEIDA,2009), o discurso da inclusão vem sendo veiculado nas políticas sociais, quase sempre em programas 
tópicos, fragmentados e seletivos, geralmente, sem um controle da sociedade, revestindo-se de legalidade.

Assim compreendendo, nos limites do que se pode sintetizar, pondera-se que, frente a uma realidade desigual, pautada em conflitos de classes e na discriminação, o sistema social tende a criar mecanismos de inclusão para amenizar uma condição social explosiva, tendo em vista as suas contradições. Da mesma forma, por contradição, na atualidade, nota-se o reconhecimento público de problemas sociais enraizados, com frequência histórica, desprezados por governantes. Contudo, as medidas tendem a ser identificadas como solução, como superação, sem considerar o fundamento da desigualdade.

\section{Inclusão nos textos e discursos sobre o PROUNI}

Como visto, o PROUNI está entre os programas que, segundo o MEC, almeja aumentar o ingresso ao ensino superior de estudantes de baixa renda. Na descrição dos programas voltados ao nível superior no site do Ministério da Educação (acesso em 17 de março de 2010), a criação do PROUNI foi assim justificada:

\footnotetext{
O programa foi criado objetivando ampliar o acesso ao ensino superior de estudantes de baixa renda, até então somente atendidos no âmbito das instituições privadas pelo Fundo de Financiamento ao Estudante do Ensino Superior (FIES), e regulamentar a concessão de bolsas nas instituições de ensino superior beneficentes de assistência social. (MEC, 2010).
}

Apesar da justificativa não recorrer expressamente ao termo inclusão social, observa-se que ao longo da trajetória do Programa tem se manifestado essa ideia nos discursos em sua defesa, pelos Presidentes do país, Ministros da Educação e entidades representativas do segmento privado. De igual forma, vários trabalhos científicos associam o PROUNI ao tema da inclusão social. 
Já a Associação Brasileira de Mantenedoras de Ensino Superior (ABMES), em 2004, considera o PROUNI um projeto de inclusão social e lamenta, no processo da sua criação, o mesmo não ser reconhecido como tal.

Lamenta-se que um programa que permite a possibilidade de acesso de alunos carentes às instituições de ensino superior, não seja reconhecido como exemplo de política de inclusão social. (ABMES, 2004, p. 11).

Na submissão do PL 3.582/2004 para aprovação do Presidente Luiz Inácio Lula da Silva, em 28 de abril de 2004, dentre as justificativas para a criação do PROUNI, consta o aumento de matrículas no ensino médio que, consequentemente, aumenta a demanda pelo ensino superior. Além disso, apresenta-se como justificativa a expansão do ensino superior privado com aumento da ociosidade de vagas, a necessidade de elevação do padrão educacional da população para se alcançar maiores níveis de desenvolvimento econômico, a regularização da filantropia, o pacto pela qualidade no ensino superior privado e o cumprimento da meta do Plano Nacional de Educação (PNE- Lei n ${ }^{\circ} 10.172$, de 09 de janeiro de 2001) de prover, até o final da década pelo menos $30 \%$ da população entre 18 e 24 anos na educação superior.

Ali, o termo inclusão social não é citado expressamente; ao invés disso, o primeiro item do documento refere-se à democratização do acesso, ao que parece, pretendendo significar "diversificação e expansão do acesso".

1. O Programa Universidade para Todos (PROUNI) visa democratizar o acesso da população de baixa renda ao ensino superior, pois, enquanto os alunos do ensino fundamental e médio estão majoritariamente matriculados em instituições públicas de ensino, o mesmo não acontece com os alunos matriculados no ensino superior, em que apenas $30 \%$ dos jovens universitários têm acesso ao ensino gratuito. (ABMES, 2004 , p. 28 , grifos das autoras).

Na justificativa para a implantação do PROUNI apresentada pelo então Ministro da Educação Interino, Fernando Haddad (Medida Provisória 213), Olh@res, Guarulhos, v. 3, n. 1, p. 76-103. Maio, 2015. 
também não se mostra a expressão inclusão social, e, sim, novamente, “democratização do ensino superior." (ABMES, 2004).

Um exemplo de publicidade que explora a imagem de democratização por parte do PROUNI refere-se à veiculada na mídia no ano $2006^{5}$, em que estudantes, com diversas características físicas (negros, brancos, orientais e com deficiências), deslocam-se em direção à universidade, seguidos da música "Para não dizer que não falei das flores", de Geraldo Vandré. Ao final, aparece a chamada: "Faça parte dessa revolução da educação brasileira”.

No Manual do Bolsista de 2008, já é possível verificar o termo inclusão social na apresentação do PROUNI:

O Programa Universidade para Todos é uma das mais bem-sucedidas ações do Ministério da Educação possibilitando o ingresso de jovens de baixa renda nas instituições de ensino superior. A concessão de bolsas de estudo a esses estudantes oferece oportunidade a milhares de jovens de ampliarem os seus conhecimentos e as chances de sucesso profissional. Ao reservar vagas para afrodescendentes, indígenas e pessoas com deficiência, o ProUni caracteriza-se por um importante mecanismo de inclusão social, estabelecendo oportunidades para vencer as desigualdades.(MEC/ PROUNI, 2008, p.2, grifos das autoras).

Por sua vez, no Manual do Bolsista de 2010, o Programa é apresentado como uma política que alia a inclusão ao mérito devido às características do seu processo seletivo, conforme descrito no seguinte trecho:

Dirigido aos estudantes egressos do ensino médio da rede pública ou da rede particular na condição de bolsistas integrais, com renda per capita familiar máxima de três salários mínimos, o PROUNI conta com um sistema de seleção informatizado e impessoal, que confere transparência e segurança ao processo. Os candidatos são selecionados pelas notas obtidas no ENEM - Exame Nacional do Ensino Médio conjugando-se, desse modo, inclusão à qualidade e mérito dos estudantes com melhores desempenhos acadêmicos.(MEC/ PROUNI, 2010, p.2, grifos das autoras).

Desde então assumido como um Programa de inclusão observa-se que na cerimônia de comemoração do bolsista PROUNI de número um milhão, a

${ }^{5}$ Disponível em: $<$ http://www.youtube.com/watch?NR=1\&v=RILoempmNeo\&feature=endscreen $>$.

Olh@res, Guarulhos, v. 3, n. 1, p. 76-103. Maio, 2015. 
Presidente Dilma Roussef referiu-se ao mesmo como uma forma de distribuição de renda e construção de oportunidades no mercado de trabalho:

E tenhamos muito orgulho do PROUNI porque o PROUNI é um dos elementos de distribuição de renda deste país. É um dos instrumentos mais importantes construídos agora, no presente, mas nós construímos a oportunidade no presente para garantir o futuro. Não tem como garantir o futuro se você não constrói um sistema de oportunidades no presente. E é isso que eu acho que o PROUNI é. (BRASIL, 2012, grifos das autoras).

De fato, é possível notar o desejo de que o PROUNI dê resposta maciça à população interessada no ingresso na educação superior, sobretudo, acolhendo os que possuem maior dificuldade em enfrentar a concorrência de vagas na maioria das instituições de educação superior públicas. É válido, nesse sentido, atentar à escolarização líquida da educação superior no Brasil (indicador de matriculados na faixa etária de 18 a 24 anos), que, em 2011, era de $14,6 \%$. A taxa aponta para uma expectativa elevada de que as políticas públicas promovam o acolhimento da população jovem excluída desse grau de ensino. Considere-se, ainda, que, segundo o PNAD (2007), $86 \%$ dos que frequentavam o nível médio o faziam em instituições públicas e que as famílias cujos estudantes frequentavam o ensino básico completo eram incapazes de arcar com as mensalidades de uma instituição de educação privada. Entre 2002 e 2003 verificou-se que mais de 60\% do orçamento das famílias de baixa renda ${ }^{6}$ estava comprometido com habitação, alimentação e transporte (IBGE, 2007).

Igualmente, na questão do PROUNI estão embutidas as necessidades do modelo econômico do país, sob o desafio de preparar recursos humanos especializados para responder a uma economia que tem apresentado taxas positivas de desenvolvimento, ou que, para enfrentar adversidades, precisa se mostrar competitiva. Decorre que o país necessita de trabalhadores mais (ou mais ou menos) qualificados, o que coloca a educação superior na

\footnotetext{
${ }^{6}$ No período da pesquisa a faixa de mais baixo rendimento familiar mensal era de até $\mathrm{R} \$ 400,00$. Olh@res, Guarulhos, v. 3, n. 1, p. 76-103. Maio, 2015.
} 
condição de avalista da ascensão social e do desenvolvimento. Assim, o PROUNI pode ser visto como uma resposta do Estado frente à demanda por educação superior por parte da população, bem como à necessidade de oferecer ao setor produtivo a força de trabalho necessária para a sua expansão.

Em face do quadro complexo, julga-se que uma pesquisa que evidencie a realidade dos envolvidos diretamente no PROUNI (os bolsistas, no âmbito do local de formação universitária), pode agregar elementos explicativos ao tema debatido.

\section{A inclusão por bolsistas do PROUNI}

$\mathrm{Na}$ pesquisa realizada ${ }^{7}$ foram entrevistados sete bolsistas de uma universidade privada que aderiu ao PROUNI, distribuídos nos cursos de Ciências Contábeis, Medicina, Pedagogia, Agronomia, Direito e Odontologia. Em síntese, seu perfil compõe-se de três homens e quatro mulheres que recebem bolsa integral do referido Programa. Do grupo, quatro são cotistas, um recebe bolsa permanência e quatro aliam trabalho com os estudos. Todos cursaram pelo menos dois semestres na instituição por meio do PROUNI e quatro não possuem nenhum membro da família com nível superior completo. Na sua totalidade, os entrevistados relataram que já haviam tentado entrar no ensino superior público e que, no momento, foram selecionados para os cursos de sua opção.

Na primeira entrevista, o bolsista do curso de Ciências Contábeis, de 42 anos de idade, relatou sentir-se um privilegiado por não ter entrado no mercado de trabalho precocemente, o que, a seu ver, significou boa qualidade de estudo e, por efeito, boa nota no Exame Nacional de Ensino Médio (ENEM). Essa situação incomum diante da sua realidade é atribuída à influência do pai:

\footnotetext{
${ }^{7}$ Sobre os relatos apresentados se fez necessário selecionar aspectos de interesse do tema ora desenvolvido, dada a extensão dos dados colhidos.

Olh@res, Guarulhos, v. 3, n. 1, p. 76-103. Maio, 2015.
} 
"Ele sempre dizia para mim e para todos os filhos que tínhamos que estudar para ser alguém na vida [...] Eu terminei o ensino médio estudando a tarde. De certa forma é um privilégio, não é qualquer família que consegue bancar um filho para estudar a tarde, hoje em dia eles vão trabalhar e estudam a noite."

O entrevistado relata, ainda, que os beneficiados do PROUNI são bem vistos na instituição por terem alcançado a bolsa devido a uma boa nota no ENEM. Ao ser questionado se já havia sofrido discriminação por ser bolsista, enfatizou:

"Não, em hipótese alguma. Não vou dizer que seja bem visto também, mas quem é bolsista do PROUNI dá uma impressão de... é chato falar assim... ser mais bem avaliado. Na minha sala a maioria é bolsista ${ }^{8}$, mas têm, eu acredito, uns $15 \%$ que não são bolsistas e a gente percebe que eles queriam ser bolsistas. Eles falam: você fez a prova e tirou uma boa nota para conseguir a bolsa. É um fator positivo, somos bem vistos."

Sobre as possíveis causas de outras pessoas não conseguirem ingressar no ensino superior, assim justifica:

"Nos dias de hoje eu acho que é acomodação não gostar de estudar, não procurar melhorar. Eu conheço muitos que estão por aí no meu raio e eu pergunto: por que não vão estudar? Muitos deles não falam nada, não se interessam, são muitos os acomodados."

A respeito da influência do seu ingresso no ensino superior sobre as pessoas do seu entorno, foi afirmativo:

\begin{abstract}
"Sim, eu tenho um exemplo claro: a minha ex-mulher era uma pessoa que nunca foi fã da escola e fez o ensino médio de uma forma não muito legal, não com afinco. Depois que comecei a fazer faculdade, comecei a conversar com ela e ela conseguiu FIES e faz Psicologia. Consegui que outras pessoas procurassem o caminho do estudo, o caminho do ensino superior."
\end{abstract}

Ao cabo, teve-se a impressão de que, para o entrevistado, ser bolsista não se ligava a uma situação de carência material exatamente, e sim de

\footnotetext{
${ }^{8} \mathrm{O}$ bolsista, ao afirmar que na sala de aula a maioria se compõe de bolsistas, referiu-se aos alunos que possuem FIES. Na verdade, esses não podem ser considerados bolsistas, já que o FIES diz respeito a um financiamento dos estudos.

Olh@res, Guarulhos, v. 3, n. 1, p. 76-103. Maio, 2015.
} 
competência por ter atingido boa nota no ENEM, daí ter sido escolhido, beneficiado pelo PROUNI, em meio a tantos outros que desejavam aquela oportunidade. Em vários momentos da entrevista percebia-se estar diante uma pessoa determinada e ciente de que essa característica repercutira na sua trajetória.

O segundo entrevistado era um bolsista do curso de Medicina, 22 anos de idade. De imediato, notava-se estar diante de quem contrariava o fluxo dos acontecimentos que comumente afetaos estudantes de origem popular. Segundo narrou, o definitivo para alcançar o objetivo, em face de uma seleção competitiva, fora uma bolsa de estudo integral no terceiro ano do ensino médio em uma escola particular e uma bolsa para realizar o curso preparatório ao ensino superior.

"Sinceramente, houve muitos professores na escola pública que me desanimaram, falaram que Medicina era impossível de fazer, mas sempre falei que eu queria fazer Medicina. Uma professora de Matemática falou que eu não ia conseguir, que era muito concorrido. $\mathrm{O}$ ensino público é muito ruim, muito fraco, mas no terceiro ano eu fui para uma escola particular, aí o nível é outro. Mas por que eu fui para lá? Aí tem a parte boa: nessa escola tinha uma professora de Biologia que sabia do meu esforço, porque eu sempre fui um bom aluno, mas eles sabiam que mesmo eu sendo bom aluno e estudando muito eu não tinha chance de concorrer com quem vinha de escola particular. Quando eu falava que eu queria fazer Medicina poucos acreditavam em mim."

O bolsista entende que o PROUNI representa uma alternativa importante para viabilizara participação dos jovens na educação superior, evidentemente, reconhecendo como definidor do seu ingresso no curso de Medicina.

"Acredito que hoje a maior dificuldade de quem não consegue ou não sabe da existência do PROUNI é devido à falta de incentivo da própria escola pública, de mostrar que existem essas alternativas, de anunciar mais em relação ao PROUNI. Ele é feito para esses alunos, e se a escola não der valor a isso continuarão só alguns sabendo disso." 
Em relação ao futuro, considera que o curso que realiza representa uma alavanca para novos acontecimentos na sua vida e de sua família, um propulsor de sonhos, os quais ele já delineia.

\begin{abstract}
"Eu acredito que, depois de formado vou ser um caminho, alguém influente que vai poder ajudar a família, facilitar as coisas. Na minha família, a situação financeira vai melhorar, ajudar a construir a minha casa, ajudar meus pais, realizar sonhos que antes não eram possíveis e que agora estão mais fáceis de serem realizados."
\end{abstract}

A terceira entrevista realizou-se com uma bolsista de 35 anos do $5^{\circ}$ semestre de Pedagogia, o curso que projetou realizar. Relata que uma irmã e uma sobrinha já concluíram o ensino superior e que da família parte o incentivo para que continue seus estudos, constituindo uma rede de apoio decisiva para "aguentar" as adversidades.

A entrevistada descreveu vivências do período da educação básica, as quais lhe impulsionaram a estudar para "ensinar diferente da forma como fui ensinada." O sentido de superação de passagens vividas, assim, se faz presente na experiência da sua formação.

Sobre o que o ensino superior pode representar na sua vida, afirmou: "Pode me auxiliar na construção do pensamento crítico, na construção de sugestões, opiniões, no entendimento do que você está falando.”

Em relação ao fato de muitas pessoas não terem acesso ao ensino superior, expressou: "É por falta de interesse, eu entrei sem cursinho mesmo, só estudando com livros e computadores, e só.”

A quarta entrevista realizou-se com uma bolsista de 38 anos do quinto semestre, também do curso de Pedagogia, que destacou as dificuldades em aliar trabalho e estudo e ingressar em um curso superior mediante uma seleção: "Tem que ter força de vontade para fazer um curso superior devido às dificuldades que passamos.” 
A quinta entrevista foi realizada com um bolsista do curso de Agronomia, de 23 anos. Para ele, o PROUNI representa uma oportunidade que o governo oferece a estudantes sem condições de arcar com os custos de uma graduação no setor privado, o que, aliás, converge com a imagem oficial construída.

O bolsista relata que para sua manutenção na universidade alia trabalho com estudos e não conta com a ajuda financeira da família, daí, provavelmente, a expectativa em relação à conclusão do curso. Em tom de euforia, expressa suas perspectivas:

\footnotetext{
"Acho que pode mudar totalmente, em todos os aspectos, não saberia como falar... Já mudou! Mudou com as pessoas ao meu redor, pois perguntam se eu faço Agronomia e me perguntam sobre horta, por exemplo. Não só esta questão, mas eles veem e falam 'que legal'. Como eu era músico não acreditavam que eu ia estudar. Meus pais ficaram muito felizes. Eles moram em fazenda no Paraguai e falei para eles ficarem lá, pois eu os ajudarei depois de formado. Também eu sinto que tenho outra visão, outras responsabilidades, eu gosto de me ocupar. Começou a mudança agora!"
}

O depoimento, como se nota, traduz a sensação de inclusão social experimentada em razão do ingresso na universidade.

A sexta entrevistada trata-se de uma bolsista de 19 anos que realiza o curso de Direito, trajetória viabilizada por uma "madrinha", que lhe presta suporte para a manutenção na universidade.

Sobre as possibilidades que podem se apresentar com a conclusão do ensino superior, entusiasmadamente, responde:

\footnotetext{
"Nossa,demais! Não tanto crescimento econômico, mas crescimento intelectual, da própria pessoa. Quando eu morava no interior eu tinha uma outra mentalidade. Quando você encara a cidade e passa a estudar um nível superior, você passa a ter não só o conhecimento da matéria, mas de uma sociedade em si. É bem diferente, acho que revolucionou a minha vida.'
}

O relato revela outro ângulo da vivência na educação superior, não bem delineado nas demais entrevistas: o despertar da consciência social. Por essa via, a bolsista acredita que desenvolveu uma nova visão da sociedade. 
O fato de ter conseguido uma bolsa do PROUNI influenciou as pessoas ao seu redor, conforme a narrativa:

\begin{abstract}
"Isso com certeza, serviu de incentivo para outras pessoas tentarem. Outras pessoas falaram que iam tentar o ENEM também, inclusive na minha sala havia uma menina que estava pensando em desistir por causa do valor da mensalidade. Eu falei para ela não desistir e ir atrás de desconto, fazer o ENEM e tentar a bolsa. Também falei para outras duas que estudaram em escola pública para tentarem o PROUNI."
\end{abstract}

Sobre o fato de a maioria das pessoas não terem acesso a um curso superior a bolsista argumenta:

\begin{abstract}
"Eu acho uma pena, mas acho que às vezes as pessoas não entram no nível superior por falta de vontade, porque o governo disponibiliza oportunidades. O PROUNI é um exemplo disso, e também as universidades federais com o sistema de cotas. Eu acho que vai um pouco da força de vontade de cada um. Tem umas pessoas que eu não sei o que acontece. Eu não me sinto melhor e nem acho que elas são inferiores, acho que elas estão nesta posição por opção, porque se quisessem poderiam estar até melhores. Hoje existem vários meios de você entrar no nível superior."
\end{abstract}

Mais uma vez se manifesta o discurso de que acessar a educação superior é uma questão de "estar disposto", de vontade pessoal, de iniciativa.

Por vincular-se ao curso de Direito, indagou-se se o PROUNI lhe parece um direito. Sua resposta revela a percepção de que a sociedade desigual deve tratar de forma específica os desiguais.

\footnotetext{
"Essa é uma questão meio polêmica, porque é um direito de todo cidadão estudar, está previsto na Constituição Federal. Eu acredito que seja um direito meu, até porque as escolas públicas, querendo ou não, não têm um ensino de qualidade como nas privadas, automaticamente, o aluno de escola pública tem um nível inferior ao aluno da escola privada. Eu acho que o governo para amenizar esse erro tem que dar oportunidade para o aluno da escola pública. Eu sou a favor da cota para o aluno de escola pública, porque não é fácil estudar em escola pública. Os alunos de escola particular possuem um nível bem melhor."
} 
Sobre a isenção fiscal concedida às instituições que aderem ao Programa, assim se posicionou:

\begin{abstract}
"Elas não pagam imposto, né? Eu acho justo porque a instituição privada não tem que dar bolsa para o aluno. Quem tem esta obrigação é o governo, então, ele usa desse artifício para beneficiar o aluno."
\end{abstract}

A bolsista, portanto, entende que o PROUNI proporciona benefício para o bolsista; entretanto, não tem clareza do benefício usufruído pela instituição formadora. Os bolsistas, aliás, expressaram pouco ou nenhum conhecimento sobre as condições que envolvem o processo de adesão ao PROUNI, além de não perceberem a instituição formadora como empresa e a educação como mercadoria.

A sétima entrevistada tem 32 anos e se vincula ao curso de Odontologia, o que suscitou entender as estratégias adotadas para se manter em um curso oneroso.

Sobre o ingresso no ensino superior relata ter sido aprovada em outro curso numa instituição pública estadual, mas preferiu Odontologia pelo prestígio, pelas possibilidades de emprego e melhoria de renda. Sua fala expressa persistência e vontade de ascender socialmente, traços comuns entre os bolsistas, como visto.

Em relação à seleção a que foi submetida para o ingresso, afirma:

\begin{abstract}
"Foi concorrido. Para mim foi difícil, porque tinha muitos candidatos e a concorrência foi alta. Fiquei um bom tempo sem estudar, fiquei parada quinze anos. Eu fiz educação de jovens e adultos, não tive ensino regular. Para eu entrar não foi fácil. Concorri com o pessoal que estava saindo do ensino médio, de escola particular. Estudei em casa sozinha por dois anos. Moro no interior e lá não tinha cursinho. Como sou técnica de enfermagem trabalhava o dia inteiro e não poderia fazer o ensino regular. Comecei a trabalhar muito cedo e tive filho cedo."
\end{abstract}

A sua permanência no curso, frente às várias exigências de materiais que o mesmo requer, foi garantida pelo emprego do esposo e pela organização que empreendem, enfrentando as despesas de forma escalonada. 
Conta que seu esposo possui nível superior, mas seus pais são analfabetos, o que levou a uma pausa emocionada no depoimento:

\begin{abstract}
"Meus pais nunca estudaram, não sabem ler nem escrever. Eles não têm noção do que é isso, eles não conseguem entender a magnitude do que é o curso de Odontologia. Para eles é normal, eu fico horrorizada de ver... eles falam que eu estou estudando como se isso fosse normal. Não é normal vindo da realidade que venho. Meu pai era pedreiro, depois virou mestre de obra. Eu fui criada na construção civil, eu levava comida para ele e ficava lá no meio dos peões o dia inteiro, junto com ele, tanto é que meus pais nunca se importaram da gente estudar. Meus irmãos só têm até a quarta série, sabem ler e escrever, e nunca se importaram com a questão de estudo."
\end{abstract}

Sobre o futuro, a bolsista relatou:

\begin{abstract}
"Acho que pode me dar mais poder financeiro, com certeza vai trazer. A primeira coisa que o estudante pensa é no poder financeiro, mas também na realização. Para mim era um sonho, eu nunca esperava fazer um curso desse, ainda mais desse nível que é a Odontologia, um curso da área da saúde."
\end{abstract}

\title{
A entrevistada acredita que a vivência na graduação seja fator decisivo no sentido de propiciar uma expectativa de vida e mudar seus rumos.
}

\footnotetext{
"Quando você não faz um curso de graduação não tem perspectiva de vida, esta é a verdade, porque você está bitolado. Não consegue crescer, por mais que você seja inteligente."
}

Questionada sobre os motivos da exclusão na educação superior, a depoente respondeu:

"Eu acho que as pessoas têm medo, elas têm medo de não
conseguirem. Eu também tinha medo, e agora estou aí no
quarto semestre. Nunca reprovei, nunca fiz exame final, e com
todas as dificuldades que tenho, ser mãe, morar em outro
município... A questão financeira é difícil, não é toda semana
que tenho dinheiro para vir. O que faz a diferença é você
buscar seu ideal, seu objetivo, isso faz a diferença."

Olh@res, Guarulhos, v. 3, n. 1, p. 76-103. Maio, 2015. 
Uma síntese dos relatos colhidos indica que para os entrevistados frequentarem a universidade representa saber enfrentar uma competição, estar preparado e, ao cabo, ser bem sucedido. Em outras palavras, os méritos individuais seriam responsáveis pela inclusão. De modo geral, está presente a ideia de estudar para "ser alguém, subir na vida". Nesse bojo, os bolsistas sentem-se escolhidos em razão de características pessoais, como determinação, persistência, foco, vontade, coragem face às dificuldades. Vislumbram um futuro de melhorias, de mudança positiva na vida em geral (condição econômica e formas de perceber o mundo), com possibilidades abertas para a realização de sonhos antes fora do seu alcance. Nessa perspectiva, incluídos, percebem-se como multiplicadores de influências positivas junto a familiares ou aos de seu convívio próximo. Outra faceta percebida, talvez um reflexo do que vem sendo exposto, refere-se à autoestima positiva, um sentimento de elevação do valor de si bem como de reconhecimento público.

A exclusão na educação superior, por sua vez, tende a ser explicada pela acomodação dos que não desejam realmente melhorar a vida, faltando-lhes interesse, vontade, determinação. A seu ver, porque "hoje existem meios de estar na educação superior", bastaria optar, decidir, perseverar.

\section{Ligando pontos para uma síntese}

Parte-se da compreensão de que a dinâmica da inclusão/exclusão refere-se a um fenômeno necessário à preservação do modelo de sociedade vigente. Dessa forma, as políticas de inclusão, ao acolher parcela dos segmentos explorados e discriminados, mantêm controladas tensões sociais e são funcionais à operacionalidade do setor produtivo.

O PROUNI, referenciado na ideia de inclusão social, foi idealizado com o propósito de ofertar vagas no setor privado destinadas a uma população marcada pela omissão do poder público, com histórico familiar de baixa Olh@res, Guarulhos, v. 3, n. 1, p. 76-103. Maio, 2015. 
renda e ausência ou baixa escolarização. Uma população, em síntese, a margem dos bens sociais básicos.

Os dados da pesquisa mostraram que parcela dos excluídos, agora incluídos em parte via o PROUNI, acredita na sua ascensão social e percebe sua vida pessoal e familiar modificada positivamente. A propósito, isso não pode ser desprezado ou minimizado, conforme atestam pesquisas com egressos da educação superior. Vargas (2011), por exemplo, revela que a diplomação na educação superior teve efeito positivo para os egressos de classes populares pesquisados, diminuindo ou amenizando a influência da origem social e oferecendo-lhes condições semelhantes no mercado de trabalho em relação aos egressos de classes mais favorecidas.

O texto revela, ainda, que inclusão social e igualdade se associam no discurso oficial, embora o referencial teórico adotado pelas autoras mostre um antagonismo conceitual entre ambos. Nesse entendimento, se incluir é acolher em parte, conservando a lógica da exclusão, igualdade, por sua vez, guarda o sentido de coletividade plena, de universalidade. Não sendo idênticos, nivelá-los pode representar uma realidade irreal.

Ao evidenciar os relatos dos bolsistas sobre sua vivência acadêmica e suas percepções sobre o PROUNI, vê-se que tal política educacional, conveniente ao sistema, igualmente se mostra conveniente a eles, promovendo, em muitos casos, a transição de uma exclusão absoluta para uma inclusão relativa. O novo status, pois, indica a transição de uma condição de extrema exploração para outra mais atenuada, com usufruto de certos bens, antes negados em absoluto. Assim, segundo os depoimentos colhidos, produzem-se mudanças na vida material dos estudantes beneficiados e no seu modo de ver o mundo e a própria existência. Mirando os incluídos, percebe-se, pois, que o contraditório PROUNI produz histórias e mudanças contraditórias, cujos efeitos precisam ser insistentemente examinados. 
Nessa perspectiva, tendo em vista a linha teórica que orientou o debate proposto, conclui-se que incluir prende-se às limitações da ordem social estabelecida, as reflete e por elas é condicionado. Todavia, nesse terreno complexo, emergem eventos que, em movimento dialético, podem vir a contrariá-las e desafiá-las. 
Referências bibliográficas

ALMEIDA, C. E. M. de. O Discurso de Inclusão nas Políticas de Educação Superior (2003 - 2008). 187 f. Tese (Doutorado em Educação). Universidade Federal de Mato Grosso do Sul, 2009.

ASSOCIAÇÃO BRASILEIRA DE MANTENEDORAS DE ENSINO SUPERIOR-ABMES. Programa Universidade para Todos. ABMES Cadernos. Brasília: ABMES, n. 13, 2004.

BONETI, Lindomar Wessler. Educação Inclusiva ou Acesso à Educação. In: 28a. RA da Associação Nacional de Pós-Graduação e Pesquisa em Educação - ANPED, 2005, Caxambu - MG. Rio de Janeiro: Edição da ANPED, 2005. v. 01 (Anais). Disponível em: <www.anped.org.br/reunioes/28/textos/gt11/gt11153int.rtf>. Acesso em: 28 ago. 2012.

BRASIL. Imprensa. Discursos. Discurso da Presidenta da República Dilma Rousseff durante cerimônia alusiva a concessão de 1 milhão de bolsas PROUNI. Disponível em: $<$ http://www2.planalto.gov.br/multimidia/galeria-de-videos/video-do-discurso-da-presidentada-republica-dilma-rousseff-durante-cerimonia-alusiva-a-concessao-de-1-milhao-de-bolsasdo-prouni-brasilia-df>. Acesso em: 27 set. 2012.

Instituto Brasileiro de Geografia e Estatística. Pesquisa de Orçamentos Familiares 2002-2003 - Perfil das despesas no Brasil. Rio de Janeiro, 2007. Disponível em: <http://www.ibge.gov.br/home/estatistica/populacao/condicaodevida/pof/2002_2003perfil/pof 2002_2003perfil.pdf>. Acesso em: 22 mar. 2012.

Pesquisa Nacional por Amostras de Domicílios. PNAD 2007. Rio de

Janeiro, 2007. Disponível em: <http://www.ibge.gov.br/home/estatistica/populacao/trabalhoerendimento/pnad2007/graficos _pdf.pdf>. Acesso em: 22 mar. 2012.

Lei n. ${ }^{\circ}$ 10.172, de 09 de janeiro de 2001. Aprova o Plano Nacional de Educação e dá outras providências. Brasília, 09 de janeiro de 2001. Disponível em: <http://www.planalto.gov.br/ccivil_03/leis/leis_2001/110172.htm>. Acesso em: 30 jan. 2011. 
Lei.$^{\circ} 11.096$, de 13 de janeiro de 2005. Institui o Programa Universidade para

Todos - PROUNI. Brasília, 13 de janeiro de 2005. Disponível em: <http://www.planalto.gov.br/ccivil_03/_ato2004-2006/2005/Lei/L11096.htm>. Acesso em: 30 jan. 2011.

Lei n. ${ }^{\circ} 12.711$, de 29 de agosto de 2012. Dispõe sobre o ingresso nas universidades federais e nas instituições federais de ensino técnico de nível médio e dá outras providências. Brasília, 29 de agosto de 2012. Disponível em: $<$ http://presrepublica.jusbrasil.com.br/legislacao/1032851/lei-12711-12>. Acesso em: 02 nov. 2013.

Lei $\mathrm{n}^{\circ}$ 9.394, de 20 de dezembro de 1996. Estabelece as diretrizes e bases da educação nacional. Brasília, 20 de dezembro de 1996. Disponível em: <http://portal.mec.gov.br/arquivos/pdf/ldb.pdf> Acesso em: 17 mar. 2010.

Ministério da Educação. PROUNI. Manual do Bolsista 2008. Brasília. Disponível em: <http://prouniportal.mec.gov.br/images/arquivos/pdf/manual_bolsista_prouni.pdf>. Acesso em: 27 set. 2012.

.Ministério da Educação. PROUNI. Manual do Bolsista 2010. Brasília. Disponível em: <http://prouniportal.mec.gov.br/images/arquivos/pdf/manual_bolsista_prouni.pdf > Acesso em: 27 set. 2012.

Ministério da Educação. Educação Superior. Programas. Brasília. Disponível em: <http://portal.mec.gov.br>. Acesso em: 09 set. 2010.

Ministério da Justiça. Portaria n. ${ }^{\circ}$ 1156, de 20 de dezembro de 2001, que Institui o Programa de Ações Afirmativas no Ministério da Justiça. Brasília, 2001.

Projeto de Lei n. ${ }^{\circ}$ 3.582, de 18 de maio de 2004. Dispõe sobre a instituição do Programa Universidade para Todos - PROUNI. Brasília, 18 de maio de 2004. Disponível em: <http://www.camara.gov.br/proposicoesWeb/fichadetramitacao?idProposicao=253965>. Acesso em: 22 fev. 2012.

Olh@res, Guarulhos, v. 3, n. 1, p. 76-103. Maio, 2015. 
CHAVES, V. L. J. Expansão da privatização/mercantilização do ensino superior brasileiro: a formação dos oligopólios. Revista Educação e Sociedade, Campinas, vol. 31, n. 111, p. 481-500, abr.- jun. 2010. Disponível em: 〈http://www.cedes.unicamp.br〉.

CUNHA, L. A. O desenvolvimento meandroso da educação brasileira entre o estado e o mercado. Revista Educação e Sociedade, Campinas, vol. 28, n. 100 - Especial p. 809-829, Out. 2007. Disponível em: 〈http://www.cedes.unicamp.br>.

GIDDENS, A. A terceira via. Reflexões sobre o impasse político atual e o futuro da socialdemocracia. Rio de Janeiro: Record, 2001.

GOERGEN, P. Educação superior na perspectiva do sistema e do plano nacional de educação. Revista Educação e Sociedade, Campinas, vol. 31, n. 112, p. 895-917, jul.-set. 2010. Disponível em: <http://www.cedes.unicamp.br>.

IPEA. A Década Inclusiva (2001-2011): Desigualdade, Pobreza e Políticas de Renda. Comunicados do Ipea. Brasília: Ipea, nº155, 2012.

JORNAL DA CIÊNCIA. E-mail 4955, de 20 de maio de 2014. Educação promove seminário sobre dez anos do Prouni. Disponível em: <www.jornaldaciencia>. Acesso em: 20 mai. 2014.

LEHER, R. Para silenciar os campi. Revista Educação e Sociedade, Campinas, vol. 25, n. 88 - Especial, p. 867-891, Out. 2004. Disponível em: 〈http://www.cedes.unicamp.br〉.

MANCEBO, D. Reforma universitária: reflexões sobre a privatização e a mercantilização do conhecimento. Revista Educação e Sociedade, Campinas, vol. 25, n. 88 - Especial p. 845866, - Out. 2004. Disponível em:〈http://www.cedes.unicamp.br〉.

MAO, T. Sobre a prática. Sobre a contradição. São Paulo: Expressão Popular, 2009.

MÉSZÁROS, I. Para além do capital: rumo a uma teoria da transição. São Paulo: Boitempo, 2002 .

OLIVEIRA, L. Os excluídos 'existem'? Notas sobre a elaboração de um novo conceito. Revista Brasileira de Ciências Sociais. São Paulo, v. 12, n. 33, p. 49-61, fev. 1997. 
PEIXOTO, M. do C. L. Inclusão social na educação superior. Série- Estudos. Campo Grande, n. 30, p. 237-266, jul./dez. 2010.

REDE BRASIL ATUAL. Em dez anos, ProUni já formou 400 mil profissionais. Metade é negra. Disponível em: <www.redebrasilatual.com.br/> Acesso em: 20 maio 2014.

SAVIANI, D. Educação: do senso comum à consciência filosófica. Campinas: Autores Associados, 2000.

SGUISSARDI, V. Reforma universitária no Brasil- 1995-2006: precária trajetória e incerto futuro. Revista Educação e Sociedade, Campinas, vol. 27, n. 96 - Especial, p. 1021-1056, out. 2006. Disponível em: 〈http://www.cedes.unicamp.br>.

SILVA, M. P. R. da. PROUNI: um programa de inclusão social e suas contradições. 190 f. Dissertação (Mestrado em Educação). Universidade Federal de Mato Grosso- Cuiabá, 2013.

SOUZA, J. S.; BONILLA, M. H. S. Exclusão/ inclusão: elementos para uma discussão. Liinc em Revista. Rio de Janeiro, v.5, n.1, p. 133-146, mar. 2009. Disponível em: < http://www.ibict.br/liinc>. Acesso em: 30 set. 2012.

VARGAS, M. de L. F. Ensino superior, assistência estudantil e mercado de trabalho: um estudo com egressos da UFMG. Revista Avaliação. Campinas; Sorocaba, v. 16, n. 1, p. 149$163,2011$.

Recebido para publicação em 12 de dezembro de 2014 Aprovado em 19 de março de 2015 